\title{
FLUID MECHANICS OF
}

\section{WASTE-WATER DISPOSAL IN THE OCEAN}

\author{
Robert C. Y. Koh and Norman H. Brooks \\ W. M. Keck Laboratories, California Institute of Technology, Pasadena, California 91109
}

\section{INTRODUCTION}

Outfall pipes into the ocean are analogous to chimneys in the atmosphere: they are each intended for returning contaminated fluids to the environment in a way that promotes adequate transport and dispersion of the waste fluids. A waste-water treatment plant and an adjoining outfall constitute a system for environmental control; it is practically never feasible to provide such complete treatment that an outfall is not necessary, nor is it common to depend entirely on an outfall with no treatment.

Although outfalls and chimneys are functionally similar, there are important differences in their relationships to the coastal waters and atmosphere respectively. Urban and industrial areas, generating waste water, are located along the shallow edge of the ocean, with often tens or even hundreds of kilometers of continental shelf between the shoreline and the deep ocean. The bottom slope on the shelf is typically less than one percent. Thus outfalls extending several kilometers offshore discharge into a body of water of large lateral extent compared to the depth, and are still remote from the main body of ocean water.

In contrast, most atmospheric contaminants are introduced at the base of the atmosphere and circulate throughout the whole atmosphere much more readily. Vertical convection mixes the troposphere rapidly in most places and the wind systems circulate the air around the globe in a matter of weeks.

Outfalls and chimneys are useful in reducing pollutant concentrations only locally. Far away from the sources, it makes little difference how the pollutants are discharged. The decay times of the pollutants are important in the choice of effective discharge strategies. For example, the problems of very persistent contaminants such as DDT cannot be alleviated by dispersion from an outfall; such pollutants must be intercepted at the source and prevented from entering the 
environment. On the other hand, degradable organic wastes, as in domestic sewage, may be effectively disposed of through a good ocean outfall. Since the decay time is only a few days, potential problems are only local, and not regional or global.
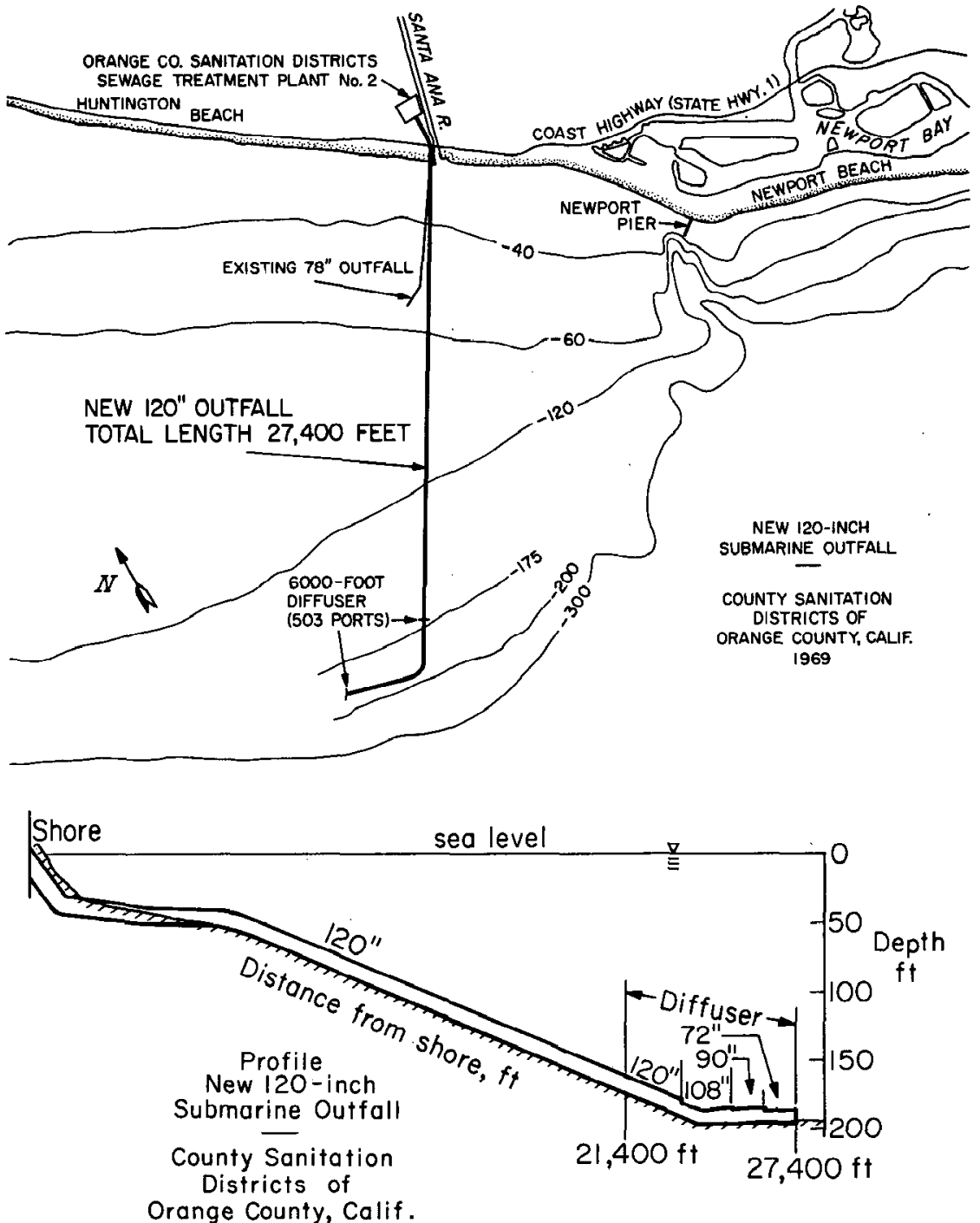

Figure 1 Schematic plan and profile of the 120 inch outfall, County Sanitation Districts of Orange County, California. 
The coastal waters are biologically productive because of the infusion of nutrients from the continents and upwelling of nutrient-rich bottom water. Man's additions of organic material and nutrients cause perturbations in the coastal ecosystems. Most past problems have resulted from excessive waste loadings very close to shore or in estuaries, that is in cases where man's effects have been overwhelming. The current practice of outfall design for large systems is to build long pipelines on the open coast to depths up to $70 \mathrm{~m}$, and to install large multiple-port (multiport) diffusers. They can achieve large initial dilutions of the order of 100 to 1 and produce submergence of the entire waste-water cloud below the surface when there is sufficient ambient density stratification. This practice has greatly improved water quality at relatively low cost. A recent study by the Southern California Coastal Water Research Project (SCCWRP) (1973) provides extensive evidence on the physical, chemical, and biological effects in Southern California coastal waters resulting from the discharge of nearly one billion gallons per day of sewage effluent through five high-dilution outfalls that produce submerged sewage fields from 8 to 12 months of the year.

Functionally, the flow in the sewer system of a city is an important part of the overall mass balance. Quantitatively, however, the total organic waste load in the sewers is only one tenth of that in refuse, which is about 6 lbs per capita daily; it is also less than one tenth of the wastes discharged into the atmosphere. The latter fact may be readily appreciated by comparing the amount of "fuel" it takes to "run" the human body compared with what is used to run your automobile or generate your share of electricity.

For coastal cities there is no better alternative to discharging waste water into the ocean. The fresh water would go to the ocean anyway if man did not divert it, and it would carry with it all the natural wastes of the land (salts and sediments). Man is a participant in the hydrologic cycle with the responsibility for providing the proper level of source control, treatment, and dispersion in the process of returning these flows to the water environment (Brooks 1973).

A typical outfall consists of a submarine pipeline roughly perpendicular to the shoreline; in the shallower water it is buried under rip-rap for wave protection, and at greater depths it is laid on the ocean floor with ballast rock on either side. At the far end there is usually a diffuser section-a manifold with many small holes to distribute the flow over a large distance. The $27,400-\mathrm{ft}$ outfall built by the Orange County Sanitation Districts and put in operation in 1971 is shown in Figure 1. The diffuser pipe is $6000 \mathrm{ft}$ long and contains 500 ports spaced at $24 \mathrm{ft}$ on each side of the pipe, plus three end ports. The side ports range in diameter from 3.0 to 4.1 inches and discharge at an average velocity (year 2020) of $13 \mathrm{fps}$. (The three end ports are 6 inches in diameter.) The outfall is designed for an average flow (year 2020) of $290 \mathrm{mgd}$ (million gallons/day) and a peak flow of $480 \mathrm{mgd}$ (Carollo Engineers 1970). Figure 2 shows a typical 24-ft section of outfall pipe with diffuser ports before laying.

The ambient water quality requirements to be met are usually set by the states and cover a variety of physical, chemical, and biological characteristics. In addition there may be effluent requirements [secondary treatment is now mandated for 


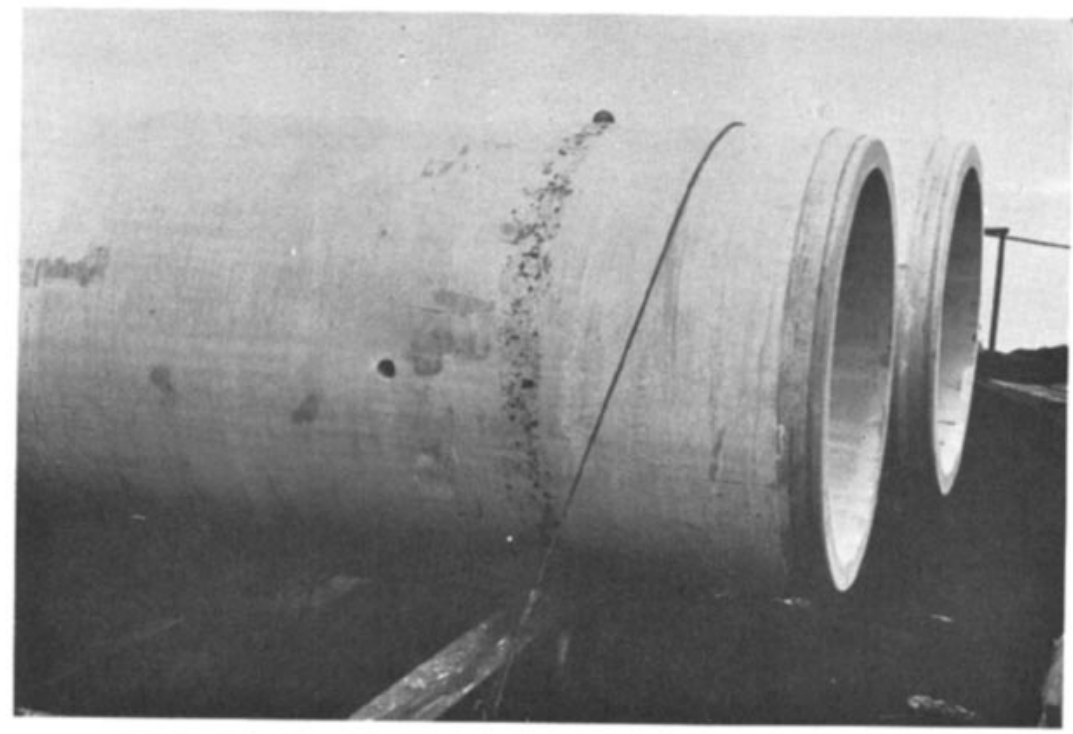

Figure 2 A reinforced concrete diffuser pipe showing a discharge port used in the 120 inch outfall of the County Sanitation Districts of Los Angeles County. (Pipe diameter $=72$ inches, port exit diameter $=3.6$ inches.)

municipal discharges by federal law (Public Law 92-500, 1972; Federal Register, August 17, 1973)]. Most states have also stiffened their requirements considerably in the last few years; see, for example, those issued by the California Water Resources Control Board, 1972.

From the point of view of fluid mechanics an important California requirement is that the initial dilution over the outfall diffuser must be greater than 100:1 for at least $50 \%$ of the time and greater than $80: 1$ for at least $90 \%$ of the time during any one-month period. Furthermore, if possible, the outfalls should be long enough to meet shoreline bacterial standards without disinfection.

The fluid-mechanics problems discussed in this review paper are in three main categories:

1. Initial jet and plume mixing in a density stratified ocean.

2. Advection and diffusion by natural processes in the ocean.

3. Hydraulic design of long multiport diffusers.

Excluded are the problems of wave forces on the submarine pipes and associated ballast stones, although of course every project must incorporate adequate wave defense. Also omitted are the usual problems of pumping, hydraulic transients, and pipe friction.

The design of outfalls for thermal discharges from steam power plants presents somewhat different problems, which have been reviewed by Harleman \& Stolzenbach 
(1972). Mainly these discharges are much larger, require smaller dilutions (order of 10:1 or less), and are located in shallower water closer to shore. Consequently, these outfalls may actively modify the whole inshore circulation and density structure. On the other hand, the waste-water discharges to be discussed herein are relatively passive in their effects on the dynamics of the coastal waters, except in the initial mixing zone.

\section{MIXING PROCESSES}

When sewage effluent is discharged through a submarine outfall diffuser, it undergoes three stages of turbulent mixing processes. First it rises as a buoyant plume, entraining (and mixing with) the ambient ocean water. This first phase of mixing carries the diluted effluent either to the surface or to a terminal level below the surface in the event there is sufficient ambient density stratification (see Figure 3). The second phase of transport is that of horizontal spreading. The sewage field, being either buoyant at the surface or homogeneous at a submerged level, tends to spread out horizontally and collapse vertically. This second phase of the establishment of a sewage field is followed by the third phase of dynamically passive turbulent diffusion and advection by the ocean currents. This last phase is dependent on the ambient ocean turbulence and the current structure. Proper design of an ocean outfall diffuser must take into consideration all of these processes, although only the first is under the direct control of the designer.

Theoretical and experimental investigations in the last two decades have greatly

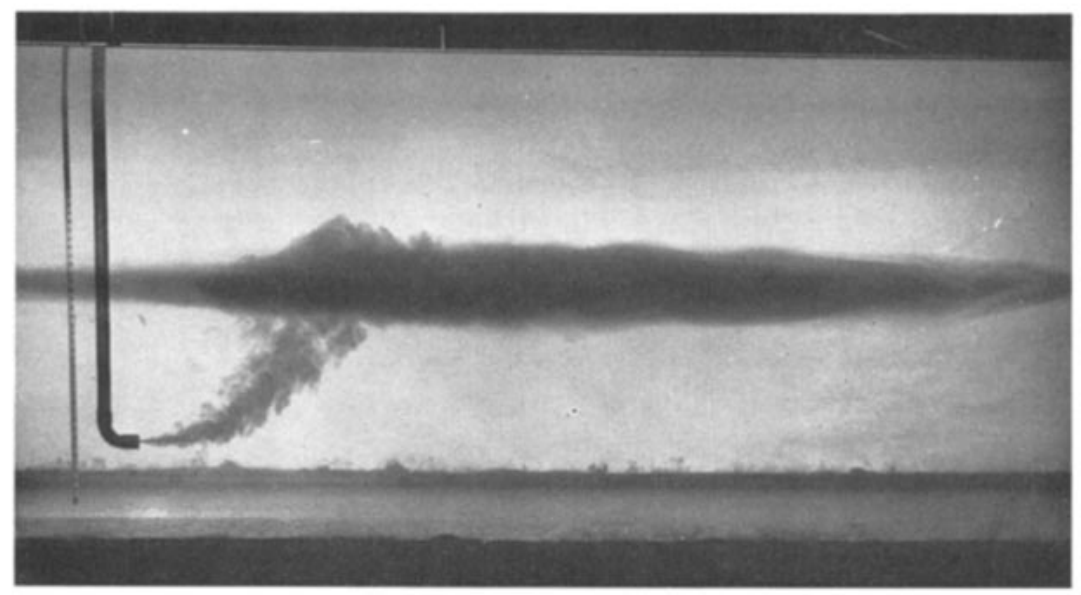

Figure 3 A buoyant jet in a laboratory tank, illustrating how the ambient density stratification prevents the jet from reaching the surface. (Jet diameter $=0.25 \mathrm{~cm}$; jet discharge $=3.1 \mathrm{cc} / \mathrm{sec} ;$ jet density $=1.001 \mathrm{gm} / \mathrm{cc} ;$ ambient density at jet level $=1.024 \mathrm{gm} / \mathrm{cc}$; ambient density stratification $\left.=7.6 \times 10^{-5} \mathrm{~cm}^{-1}\right)$ (from Fan \& Brooks 1969). 
192

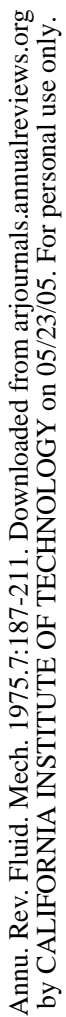

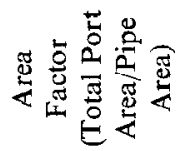
还惫

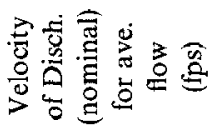

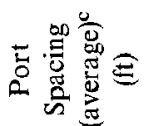

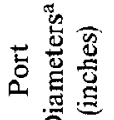

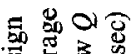

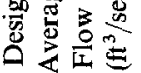

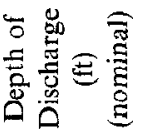

胥 营

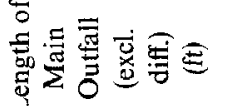

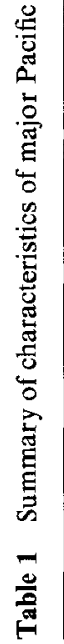

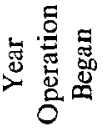

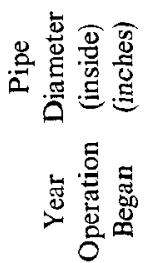

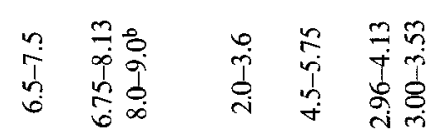

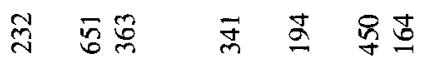

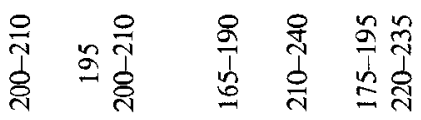

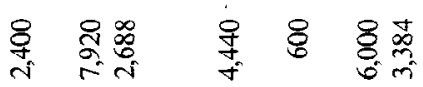

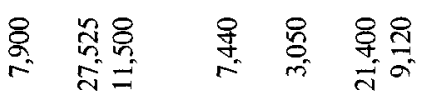

タ オீ응 잃

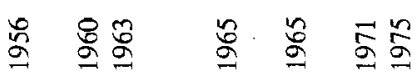

\%

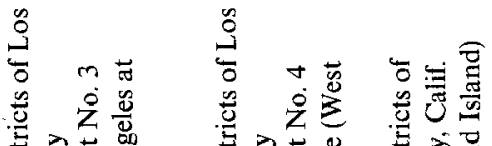

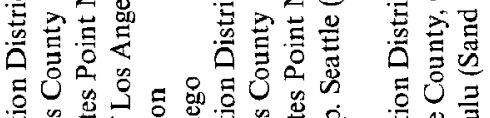

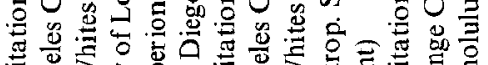

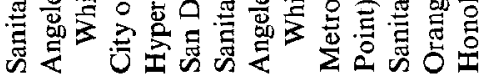

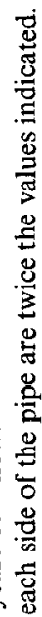

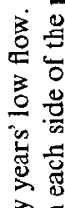
글 密占 恶总

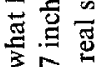
ถู่ 㑒 齐它 营焉 응 을 룰 3 \& 淧焉 요 总总总 은 蛋 旁 
advanced the understanding of buoyant jets and plumes. The second phase of dynamical spreading has not been as intensely investigated, although a few exploratory studies have been made. Passive turbulent diffusion in the ocean has also received much attention, but there has been little attention to the description of advection (and associated dispersion by shear effects) by unsteady currents, including tidal effects.

Before embarking on a discussion of these processes, it is of interest to compare the order of magnitude of the various components of a typical multiport diffusion structure for waste water. Table 1 summarizes the parameters for several such structures. Typically, the overall length of a diffuser is an order of magnitude larger than the depth, which in turn is an order of magnitude larger than the pipe diameter and port spacing, which again are an order of magnitude larger than the typical port diameters. Therefore, the flow pattern starts as a number of small individual submerged jets driven first by their initial momentum and buoyancy; after traversing about three times their spacing, they will merge into a dilute plume whose rise may be gradually retarded and stopped by the ambient density stratification. A row of small ports in a diffuser may often be analyzed approximately as a line source. However, such an approximation is not good if the ports are far apart or the stratification is strong near the bottom, because the individual buoyant jets may be stopped by the water surface or by the density structure before merging.

Other factors are important in the flow pattern near the source. If the current is strong, the buoyant jets will be bent over and probably undergo more dilution; the wake of the pipe may even dominate the initial jet mixing, as shown in the model experiment in Figure 4. Secondly, if the depth is shallow, the flow of entrainment water into the mixing zone may be so impeded that the buoyant-plume theory based on assuming an infinite flow field is completely invalid. This is likely to be the case for thermal outfalls such as those discussed in detail by Jirka \& Harleman (1973), who showed that the overall dilution achieved may depend on the nature of the stratified counterflow (diluting water flowing in toward the outfall underneath the diluted effluent flowing away).

\section{Mixing in Turbulent Buoyant Jets and Plumes}

A turbulent buoyant jet is a submerged jet with an initial buoyancy that continues to drive it upward and tends to make the columnar flow similar to that of a pure plume, defined as a source of buoyancy without initial momentum flux. Most outfalls discharge horizontally to achieve more dilution near the bottom and a longer jet trajectory; but for low discharge velocities in deep water, the initial orientation is of little significance.

Numerous investigators (e.g. Morton, Taylor \& Turner 1956, Abraham 1963, Fan 1967, and Liseth 1970) have attacked the problem of turbulent buoyant jets in an otherwise undisturbed environment. Most of the investigations assume some model for the jet entrainment mechanism and presume that cross-sectional profiles of velocity and density deficiency are similar. Density variations are assumed 

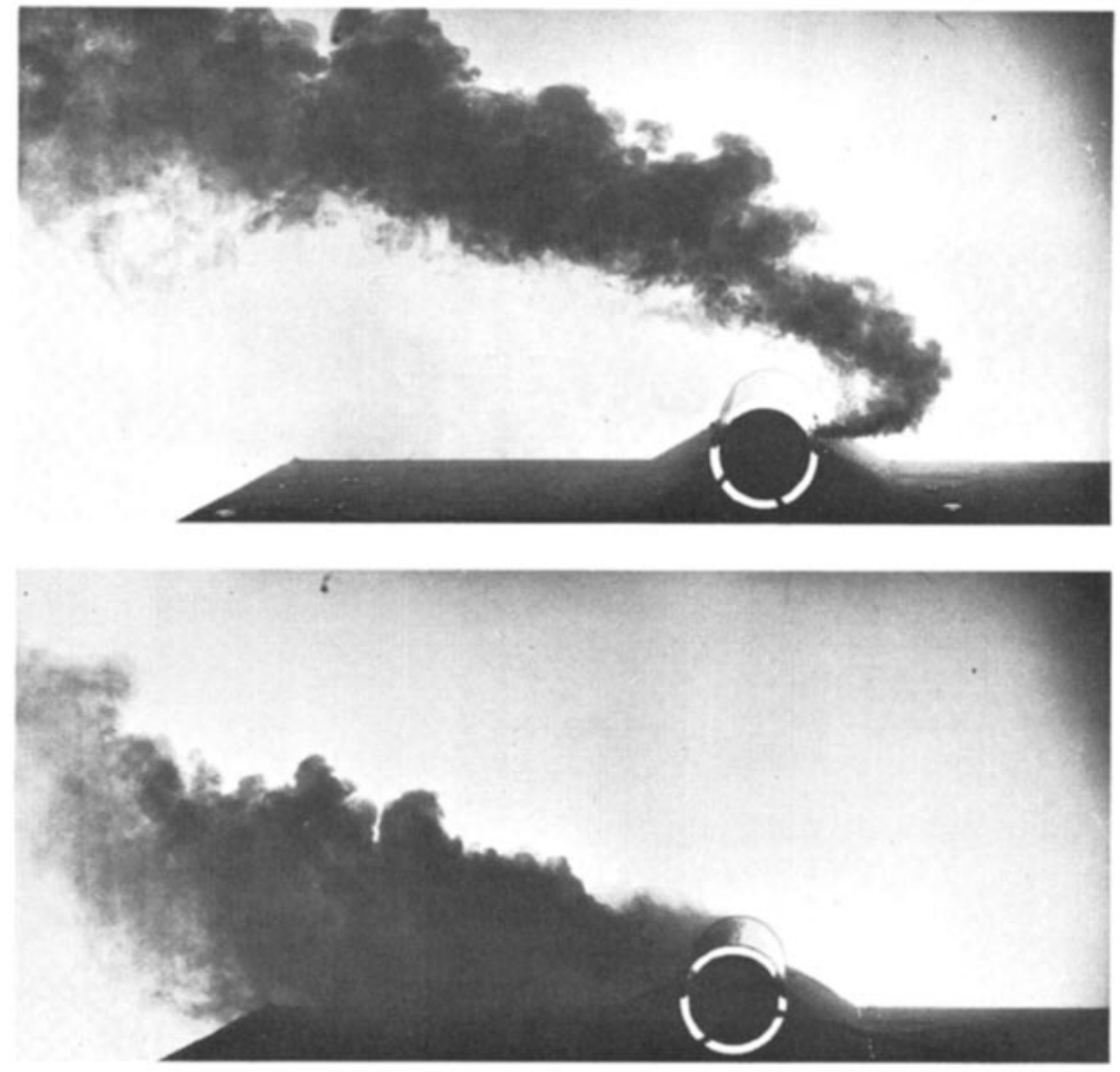

Figure 4 Buoyant jets on the sides of diffuser pipe issuing horizontally into a current (laboratory simulation of a single port in the diffuser).

small and only important in the buoyancy terms (Boussinesq approximation). The equations of conservation of mass, momentum, and buoyancy fluxes can then be integrated over the jet cross section to yield a set of ordinary simultaneous differential equations. The solution of this initial-value problem yields the gross properties of the jet behavior such as centerline velocity, dilution, jet size, and trajectory as a function of distance along the trajectory. In this approach, the curvature of the plume trajectory is also presumed small in the case of nonvertical discharge.

Laboratory experiments on simple momentum jets reveal that the velocity distribution across the jet is very nearly Gaussian for both a two-dimensional slot jet and an axisymmetrical round jet. For example, the experiments of Albertson et al (1950) showed that the following empirical relations hold for a distance $y$ along the jet that is larger than several jet widths or diameters: 
Slot Jet

Kinematic momentum flux (constant)

$u(x, y) / u_{\max }(y)$

$u_{\max }(y)$, centerline velocity

$b(y)$, measure of jet width

Volume flux

$$
\begin{array}{ll}
J=B_{0} u_{0}^{2} & K=\frac{1}{4} \pi D_{0}^{2} u_{0}^{2} \\
\exp \left(-x^{2} / b^{2}\right) & \exp \left(-x^{2} / b^{2}\right) \\
2.28(J / y)^{1 / 2} & 7 K^{1 / 2} / y \\
0.154 y & 0.115 y \\
q=0.624(J y)^{1 / 2} & Q=0.288 K^{1 / 2} y
\end{array}
$$

(Here $B_{0}$ and $D_{0}$ are the initial jet width and diameter respectively: $u_{0}$ is the discharge velocity.)

For the round jet the volume flux $Q(y)$ increases with $y$, indicating that the rate of entrainment is $d Q / d y=0.288 K^{1 / 2}$, which is proportional to the product $u_{\max } b$. For the slot jet, we have $d q / d y=0.312(J / y)^{1 / 2}$, which is proportional to $u_{\max }$. In either case, the rate of entrainment is proportional to the product of the jet centerline velocity and the jet periphery. If the jet periphery is taken to be $2 \pi b$ for the round jet and 2 (for the two sides) for the slot jet, then the proportionality constants (commonly referred to as entrainment coefficients) are $\alpha_{j r}=0.057$ and $\alpha_{j s}=0.068$ for the round and slot jets respectively. Other laboratory experiments (e.g. Ricou \& Spalding 1961, Mih \& Hoopes 1972) show similar results with only small changes in the values of $\alpha_{j r}$ and $\alpha_{j s}$.

Laboratory experiments on simple plumes (source of buoyancy only) reveal that they can also be adequately characterized by an entrainment coefficient. Experimental results (Rouse, Yih \& Humphreys 1952, Lee \& Emmons 1951) yield $\alpha_{p r}=0.082$ and $\alpha_{p s}=0.16$.

It is further found that the rates of spread of momentum and buoyancy (or density defect) are not necessarily the same. This is commonly characterized by a coefficient $\lambda$ such that the normalized velocity distribution is $\exp \left(-x^{2} / b^{2}\right)$, while the buoyancy distribution is $\exp \left(-x^{2} / \lambda^{2} b^{2}\right)$. Empirical values of $\lambda$ are found to be $\lambda_{r}=1.16$ and $\lambda_{s}=0.9$ for simple plumes.

While the behavior of a simple jet (source of momentum flux only) and a simple plume (source of buoyancy flux only) can both be characterized by a constant entrainment coefficient, this cannot be simply generalized to the case of a buoyant jet that in general is a source of mass, momentum, and buoyancy fluxes. The difficulty is clear when one compares the numerical values of the empirically determined entrainment coefficients $\alpha_{j r}$ with $\alpha_{p r}$ and $\alpha_{j s}$ with $\alpha_{p s}$. For the round case, the plume entrainment coefficient $\alpha_{p r}$ is about $45 \%$ higher than $\alpha_{j r}$, while for the slot case $\alpha_{p s}$ is about twice $\alpha_{j s}$. In a buoyant jet, one might expect that near the source, the entrainment would be close to that found in a jet, while it gradually approaches that for a plume.

The question of entrainment has not yet been completely resolved. Numerous investigators have, however, employed different assumptions for the entrainment function. For example, Priestley \& Ball (1955) replaced the entrainment assumption by using the kinetic energy equation and assuming instead a form for the distribution of Reynolds stress. Fox (1970) attempted to deduce the form of the 
entrainment function on the basis of incorporating the conservation equation for energy. Abraham (1963) replaced the entrainment assumption by essentially assuming a rate of spread of the jet, while Telford (1966) assumed that the entrainment was proportional to the mean square turbulence intensity per unit mass. List \& Imberger (1973), through dimensional reasoning and experimental data, deduced that $\alpha$ and $\lambda$ must be functions of the local Froude number and local jet spreading angle in the case of a vertical buoyant jet in a uniform environment. For the round jet, they found from experimental data that the entrainment coefficient $\alpha$ is a linear function of the inverse of the local densimetric Froude number; however, $\lambda_{r}$ is a constant equal to 1.16 . If one accepts the values $\alpha_{j r}=0.057$ and $\alpha_{p r}=0.082$ (both being commonly used), then according to List \& Imberger

$$
\alpha_{r}=0.057+\frac{0.083}{F^{2}},
$$

where $F^{2}=m^{5 / 2} / \mu^{2} \beta$ with $m$ being the kinematic momentum flux, $\mu$ the volume flux, and $\beta$ the buoyancy flux locally past a horizontal plane. Their result is equivalent to assuming that the jet spreading angle is constant and is also in accordance with the result of Priestley \& Ball (1955). Experimental results for the two-dimensional case are not sufficient for List and Imberger to obtain a similar expression for $\alpha_{s}$.

The simplest generalization of the entrainment function (as well as the one most frequently used) is that $\alpha_{r}$ and $\alpha_{s}$ are constants even in a buoyant jet. For practizal application the plume values of $\alpha$ are usually assumed because buoyant jets appear to become rapidly "plume-like," with the "jet-like" region occurring only near the source. Using the assumption of constant entrainment coefficient $\alpha$, Morton, Taylor \& Turner (1956) and Brooks \& Koh (1965) examined respectively the round and slot jets into an ambient fluid with a stable linear density stratification. (The extension of a constant entrainment coefficient to a density-stratified ambient involves yet another assumed generalization.) Fan (1967) extended the analysis to include inclined round jets (while still assuming $\alpha_{r}$ to be constant) and performed a comprehensive set of laboratory experiments showing that the assumption that $\alpha_{r}$ is a constant is quite good for his range of tests. Fan \& Brooks (1969), encouraged by the favorable comparison, presented numerical solution curves for both round and slot jets for a variety of cases (including variable angle of discharge) to facilitate design of waste-water outfalls.

A typical outfall diffusion structure contains many discharge ports on both sides of the pipe. The effect of jet interference and the gradual formation of a line plume were investigated experimentally by Liseth (1970), who found that the horizontal momentum of the two rows of ports was quickly cancelled out. The jets from the two sides of the pipe tend to be pulled together into a single line plume because of the lack of ambient diluting water in the space between the two rows of ports.

Similar integral techniques have also been applied to the round jet in a flowing cross stream (e.g. Fan 1967, Hirst 1971, Hoult \& Weil 1972, Abraham 1970). This 
problem is similar to that of the rise of a chimney plume in a wind (e.g. Csanady 1961, 1965, Bringfelt 1968, 1969, Slawson \& Csanady 1967, 1971, and Fay 1973). Since a waste-water outfall is usually quite large compared with the size of a single port, the combination of a current and the presence of the pipe itself can lead to some rather complex mixing. In particular, for a strong current normal to the diffuser pipe, the discharge on the downstream side, being in the wake of the pipe, can be expected to receive much more mixing (cf Figure 4). The buoyant slot jet in a cross stream is made more complex due to the inability of the upstream water to reach the back side of the jet. Cederwall (1971) examined this problem in a laboratory flume and delineated various types of flow regimes possible. However, end effects for a finite line diffuser may be important because ambient water can flow around the ends and be entrained on the downcurrent side of the plume.

\section{Simple Line Plume}

The equations for the case of a vertical-slot buoyant jet into a stratified fluid will be summarized below to illustrate the basic assumptions. The solution is given for the special case of a simple line plume (line source of buoyancy only) in a uniform environment. By experience it is found that for deep outfalls the line plume results are often good first approximations.

Referring to Figure 5, assume that 1 . the ambient fluid is infinite in extent, stably stratified, and motionless (except for the entrainment current); 2 . the density variations are small and are only important in the buoyancy terms; 3 . the density anomaly is a linear function of the stratifying agent (salt concentration or temperature); 4. velocity and buoyancy profiles are self-similar; 5 . the entrainment coefficient is constant; and 6. the plume is fully turbulent. For a slot jet, the
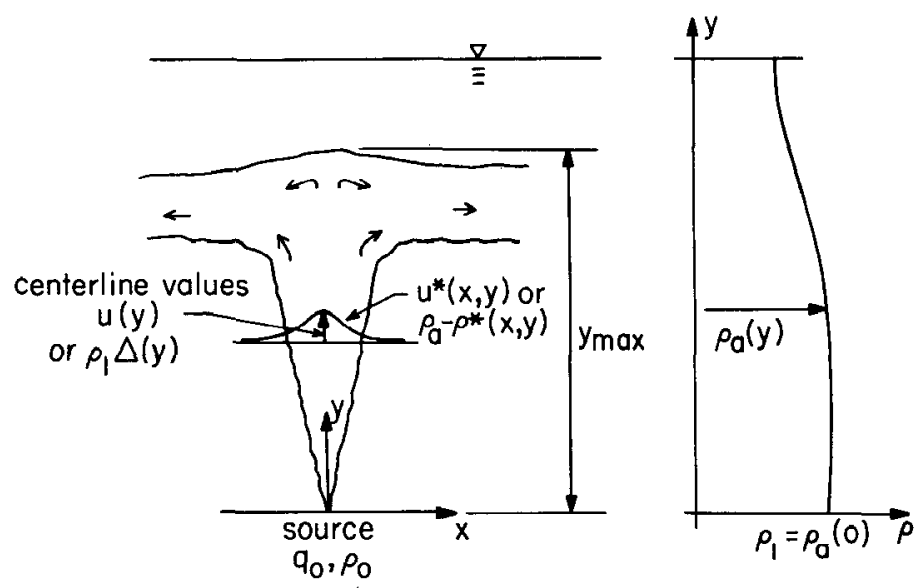

Figure 5 Definition sketch of line plume in a stratified environment. 
equations of conservation for mass, momentum, and buoyancy fluxes respectively can be written as (see e.g. Brooks \& Koh 1965):

$$
\begin{aligned}
& \rho \frac{d}{d y}\left\{\int_{-\infty}^{\infty} u^{*} d x\right\}=2 \alpha_{s} u \rho_{a}, \\
& \rho \frac{d}{d y}\left\{\int_{-\infty}^{\infty} u^{* 2} d x\right\}=g \int_{-\infty}^{\infty}\left(\rho_{a}-\rho^{*}\right) d x, \\
& \frac{d}{d y}\left\{\int_{-\infty}^{\infty} g\left(\rho_{1}-\rho^{*}\right) u^{*} d x\right\}=2 \alpha_{s} g\left(\rho_{1}-\rho_{a}\right) u .
\end{aligned}
$$

The symbols are defined in Figure 5. The first equation indicates that the rate of change of volume flux equals the entrainment flow per unit vertical length; the second that the rate of increase of momentum flux equals the buoyant force per unit length; and the third that the rate of increase of buoyancy flux (relative to the ambient density at the source level) is equal to the entrained buoyancy flux per unit length.

On the basis of jet and plume experiments, it will be further assumed that the cross-sectional profiles of buoyancy and velocity are Gaussian, with the simplification that the spreading ratio $\lambda=1$, namely:

$$
\begin{aligned}
& u^{*}(x, y)=u(y) \exp \left(-x^{2} / b^{2}\right) \\
& \frac{\rho_{a}(y)-\rho^{*}(x, y)}{\rho_{1}}=\Delta(y) \exp \left(-x^{2} / b^{2}\right)
\end{aligned}
$$

Substituting into (1), (2), and (3) and performing the integrations yields:

$$
\begin{aligned}
& \frac{d(u b)}{d y}=\frac{2 \alpha_{s} u}{\pi^{1 / 2}} \\
& \frac{d}{d y}\left(u^{2} b\right)=2^{1 / 2} g b \Delta \\
& g \frac{d}{d y}(u b \Delta)=-2^{1 / 2} u b G \quad\left(G=\frac{-g}{\rho_{1}} \frac{d \rho_{a}}{d y}\right) .
\end{aligned}
$$

The boundary conditions are as follows: $y=0, u=u_{0}, b=b_{0}$, and $\Delta=\Delta_{0}=$ $1-\rho_{0} / \rho_{1}$.

The solution of the equations can be readily performed numerically for any given ambient density profile. Computer programs are available in the literature to solve the initial-value problem based on this type of analysis in both stratified and unstratified cases, for various geometrical configurations (such as round jet, slot jet, or a row of equally spaced round jets) and various discharge angles (see Ditmars 1969, Sotil 1971 and Koh \& Fan 1970).

For the case of a simple line plume in a uniform environment $\left(\rho_{a}=\rho_{1}\right)$, the solution is particularly simple. It can be readily deduced for this case that: 


$$
\begin{aligned}
& u=u_{0}=\left(\beta_{0} / \alpha_{s}\right)^{1 / 3} \\
& b=2 \pi^{-1 / 2} \alpha_{s} y \\
& g \Delta=\frac{\beta_{0}}{2^{1 / 2} u_{0} \alpha_{s} y}
\end{aligned}
$$

where $\beta_{0}=q_{0}\left[\left(\rho_{1}-\rho_{0}\right) g\right] / \rho_{1}=q_{0} g_{0}{ }^{\prime}=$ initial buoyancy flux. The centerline dilution of a conservative tracer $S_{c}$ is found by the equation of conservation of flux of the tracer, which reduces to

$$
\left(\frac{1}{2} \pi\right)^{1 / 2} c u b=c_{0} q_{0}
$$

or

$$
S_{c}=c_{0} / c=2^{1 / 2} \alpha_{s}^{2 / 3} g_{0}^{\prime 1 / 3} q_{0}^{-2 / 3} y
$$

for $\alpha_{s}=0.14$ (as recommended by Brooks 1973):

$$
S_{c}=0.38 g_{0}^{\prime 1 / 3} q_{0}^{-2 / 3} y=0.38 g_{0}^{\prime 1 / 3} Q^{-2 / 3} L^{2 / 3} y
$$

where $L$ is the overall length of a diffuser and $Q$ is the total discharge, $Q=L q_{0}$. For example, in a given situation the dilution increases as the first power of $y$ but only as the $2 / 3$ power of $L$; the optimum choice of discharge depth and diffuser length thus depends on the topography of the site. Note also that when a row of ports at spacing $s$ is approximated by a line source, $q_{0}=Q_{\text {port }} / s$.

For a uniformly stratified environment $(G=$ const) the solution for the simple buoyant plume gives (Brooks 1973):

$$
S_{t}=0.31 g_{0}^{\prime 1 / 3} q_{0}^{-2 / 3} y_{\max }=0.31 g_{0}^{\prime 1 / 3} Q^{-2 / 3} L^{2 / 3} y_{\max }
$$

where $S_{t}$ is the terminal centerline dilution and $y_{\max }$ is the maximum height of rise of the waste-water plume given by

$$
y_{\max }=2.84\left(g_{0}^{\prime} q_{0}\right)^{1 / 3} G^{-1 / 2} .
$$

For horizontal slot discharge with typical values for the initial normalized jet momentum flux for sewage outfalls, the solution of the problem is approximately (Brooks 1973):

$$
S_{t}=0.36 g_{0}^{\prime 1 / 3} q_{0}^{-2 / 3} y_{\max }=0.36 g_{0}^{\prime 1 / 3} Q^{-2 / 3} L^{2 / 3} y_{\max }
$$

and

$$
y_{\max }=2.5\left(g_{0}^{\prime} q_{0}\right)^{1 / 3} G^{-1 / 2} .
$$

Similar results for the individual round jet can also be found in Brooks (1973).

\section{Gravitational Spreading of the Waste-Water Field and the Effect of} Blocking

The analysis of buoyant jets assumes that entrainment of the ambient fluid occurs throughout the travel of the jet. Referring to Figure 6, it is clear that dilution 


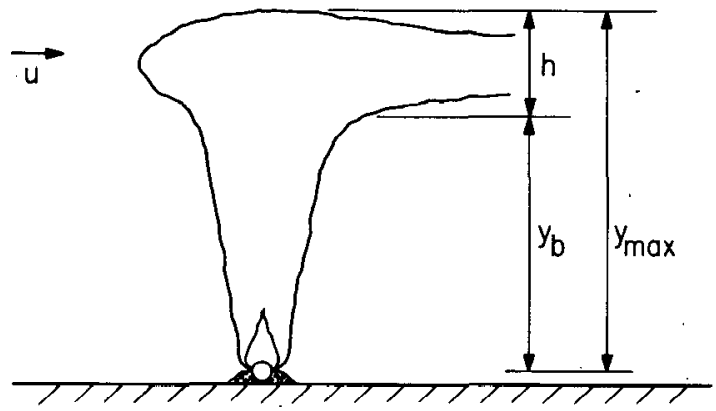

Figure 6 Schematic diagram of blocking of part of the water column by the waste-water field.

which results from the mixing must effectively cease for $y>y_{b}$. The presence of the spreading waste field blocks further dilution above $y_{b}$. For design purposes, it is important to determine the quantity $y_{b}$ or equivalently $h=y_{\max }-y_{b}$, the thickness of the waste-water field.

The effect of blocking for a line source perpendicular to the current can be estimated by invoking continuity of the waste flow as was done by Brooks (1973). By further assuming that the dilution is proportional to the vertical distance from the source, he obtained for $S$, the average dilution in the cloud,

$$
S=S_{t} 2^{1 / 2}(1+P)^{-1}
$$

where

$$
P=\frac{2^{1 / 2} Q S_{\mathrm{t}}}{u w y_{\max }}
$$

Here we have $Q=$ total waste-water flow; $u=$ ocean current speed; $w=$ width of waste-water field normal to current; $y_{\max }=$ maximum height of rise by (16); and $S_{t}=$ centerline dilution in the absence of blocking. This result should be used with caution because only continuity is used with no dynamic considerations. For $u$ vanishingly small, the estimated $S$ tends to be too small. The thickness of the waste field under the same assumptions is obtained to be

$$
h=y_{\max }-y_{b}=\frac{P}{1+P} y_{\max } \text {. }
$$

For an ocean current essentially normal to the diffuser, an estimate of ' $w$ may be taken to be the width of the diffuser normal to the current.

For a current parallel to the diffuser alignment, the value of $w$ can be estimated on the basis of buoyancy spreading. The spreading of a buoyant fluid 
on the surface of an otherwise stagnant ambient has been examined by Sharp (1969) and Koh \& Fan (1970) in relation to waste-water discharges. The problem is also somewhat similar to oil spreading on water and to the operation of locks between fresh water and salt water bodies. In the following, the case when the ambient fluid is not stratified will be examined. If it is assumed that the development of the waste-water field for a parallel current can be approximated by the time-dependent release of a buoyant fluid starting impulsively at $t=0$, then by a Galilean transformation and the application of dimensional analysis it follows that

$$
w=K\left(g_{0}^{\prime} q_{0}\right)^{1 / 3} x / u,
$$

where $x$ is the horizontal distance along the diffuser, $u$ is the parallel current speed, and $K$ is a constant which must be determined experimentally. If this is substituted into (20), using $L$ for $x$, it is found that, for $d=$ depth,

$$
P=\frac{2^{1 / 2} Q S_{t}}{K\left(g_{0}^{\prime} q_{0}\right)^{1 / 3} L d}
$$

which, in conjunction with (13), gives

$$
P=2 \alpha_{s}^{2 / 3} / K
$$

Thus the average dilution $S$ on the surface, which includes the effect of blocking by a parallel current, is

$$
S=B g_{0}^{\prime 1 / 3} q_{0}^{-2 / 3} d=B g_{0}^{\prime 1 / 3} Q^{-2 / 3} L^{2 / 3} d
$$

where $B=2 \alpha_{s}^{2 / 3} K /\left(K+2 \alpha_{s}^{2 / 3}\right)$. The thickness of the waste field is then

$$
h=2 \alpha_{s}^{2 / 3} d /\left(K+2 \alpha_{s}^{2 / 3}\right) \text {. }
$$

Exploratory experiments have been performed by the writers using a model multiport diffuser in an attempt to determine $K$. The value found varied between 1 and 1.5 and averaged 1.2. When $\alpha_{s}=0.14$ and $K=1.2$ are used, (26) gives $h \approx 0.3 d$.

For the stratified case the optimum depth and length of an outfall diffuser depends on the density structure as well as the topography because $y_{\max }$ is not directly related to the total depth. Therefore, in practical applications to the design of waste-water outfall diffusers, it is first necessary to select design density profiles since the ocean density structure changes with both season and time of day. Actual measured density profiles are seldom linear with depth. For preliminary design purposes, it is generally sufficient to employ $(17-20)$, where $G$ is taken to be the equivalent uniform gradient between $y=0$ and $y=y_{\max }$. In this manner, a variety of candidate designs may be evaluated quickly. Figures 7 and 8 show the results obtained by the writers during the design effort of the Sand Island outfall for the City and County of Honolulu (R. M. Towill Corp. 1972). In Figure 8, the depth of submergence of the waste-water field is plotted against the mean centerline dilution (for a parallel current and a $1 \mathrm{fps}$ perpendicular current). Lines are 
shown joining the results for the various flow rates and the selected density profiles (see Figure 7). It may be rcadily observed that, for a given flow rate, dilution and submergence are inversely related. Deep submergence may not be desirable due to the attendant small dilution and the later possibility of upwelling.

Qualitatively, submergence of the sewage field in a stratified ocean occurs because the fresh water jets mix with so much cold bottom water that they become neutrally buoyant in the water column before rising to the surface (see Figure 3). Because of the balance of heat and salt effects on density, the submerged cloud may further break up slowly by double-diffusive effects (or salt fingering) as described by Fischer (1971), although the effect is expected to be smaller in the field than in Fischer's laboratory observations.

The preceding discussion is intended to illustrate the type of analysis involved because limitations on space preclude a comprehensive development of the subject. For a recent detailed presentation with emphasis on outfall applications, the reader is referred to Brooks (1973).

\section{Further Diffusion in the Ocean}

Following the buoyant rise of the waste plume and the establishment of the waste field, further dispersion occurs via turbulent diffusion in the ocean. An essentially Fickian approach is used in most ocean diffusion studies, that is, eddy diffusion coefficients are used to characterize the process. Available data indicate that at least two diffusion coefficients are necessary, one in the horizontal and the other in the vertical direction. Ocean diffusion studies have been concentrated on the

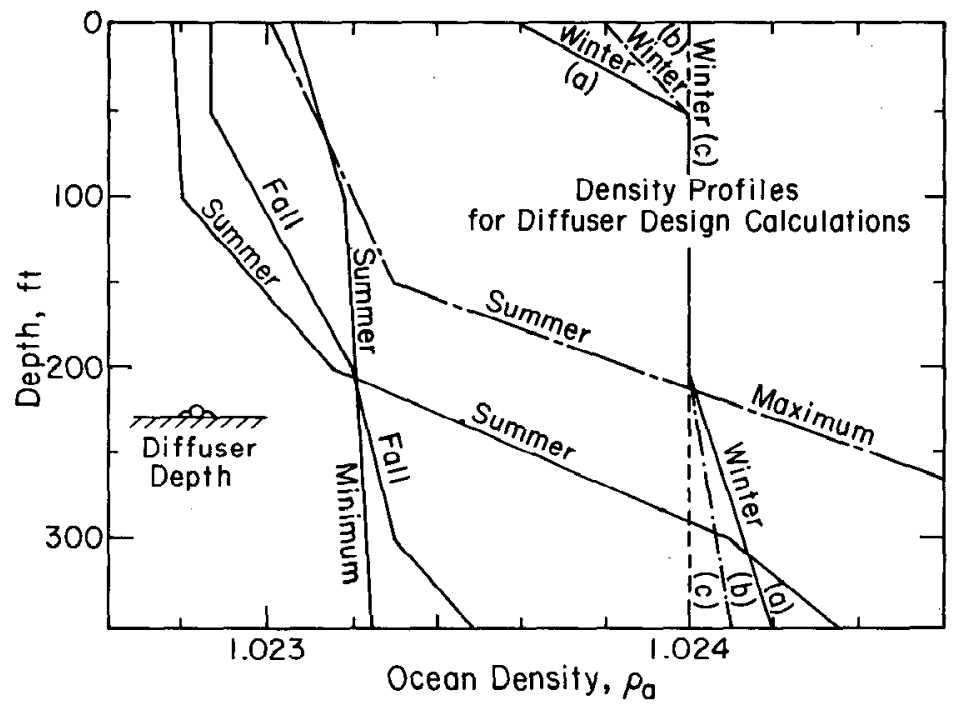

Figure 7 Design density profiles for the Sand Island outfall, Honolulu, Hawaii (from R. M. Towill Corp. 1972). 


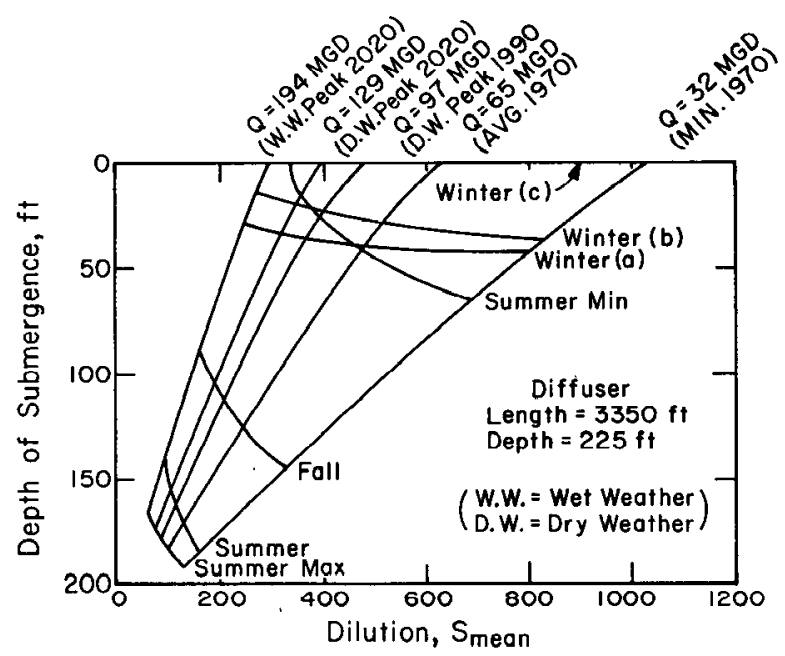

Figure 8 Dilution and submergence characteristics for the Sand Island outfall diffuser, Honolulu, Hawaii (from R. M. Towill Corp. 1972).

investigations of horizontal turbulent diffusion with but a relatively poor understanding of vertical mixing processes.

Numerous references are available in the literature on horizontal diffusion in the ocean and the reader is referred to Okubo $(1962,1968,1971)$ for summary of approaches and field data. A recent book by Csanady (1973) covers many aspects of turbulent diffusion in the environment in general.

\section{Horizontal Diffusion Coefficient in the Ocean}

Measured values of $K_{x}$, the horizontal diffusion coefficient, vary over many orders of magnitude and are found to be correlated with the size of the diffusing patch. Although data scatter is significant, the general trend follows Richardson's four-thirds power law (Richardson 1926), that is,

$$
K_{x}=A L^{4 / 3}, \quad 10^{-1} \leqq L \leqq 10^{8} \mathrm{ft},
$$

where $L$ is the size of the diffusing patch. The value of $A$ is found to vary from $1.5 \times 10^{-4}$ to $5 \times 10^{-3} \mathrm{ft}^{2 / 3} / \mathrm{sec}$. Practically all measurements are made on the ocean surface. Schuert (1970) reported on an experiment in water $300 \mathrm{~m}$ deep off Oahu, Hawaii, where the horizontal diffusion coefficient was found to be in the range obtained previously on the ocean surface.

Several authors have also investigated the effect of density stratification on $K_{x}$. However, while some (e.g. Ozmidov 1965) suggest that $K_{x}$ increases with stratification, others (e.g. Kolesnikov et al 1964) found that $K_{x}$ decreases with stratification. Laboratory data of Webster (1964) in a wind tunnel showed that while the turbulent vertical transport decreases with increasing Richardson number the 


\section{4 КОH \& BROOKS}

horizontal transport is not materially affected. Foxworthy's (1968) data also showed no correlation of $K_{x}$ with stability.

It can be readily inferred in analogy with Taylor dispersion in tubes that current shear would have a significant effect on the apparent horizontal diffusion (Saffman 1962, Carter \& Okubo 1965, Csanady 1966). Since shear is not measured in a typical field experiment, its effect may cloud the data. However, field experiments with drift cards that presumably would not be influenced by vertical shear show no significant difference from those with dye.

The effect of total depth on $K_{x}$ was investigated by Ozmidov (1959). His results suggest a slight increase in $K_{x}$ for large depth.

In summary, there seems to be no question that $K_{x}$ increases with the scale of the phenomenon. Correlation of data with the four-thirds power law is encouraging but by no means conclusive. There is no evidence of any significant dependence of $K_{x}$ on stability or depth.

\section{Vertical Turbulent Diffusion Coefficient}

In contrast with the relative abundance of data for horizontal diffusion on the sea surface, there is a scarcity of data for vertical diffusion. Reported values (usually inferred, e.g. from temperature and salinity data) range from as low as $4 \times 10^{-2} \mathrm{~cm}^{2} / \mathrm{sec}$ to as high as $200 \mathrm{~cm}^{2} / \mathrm{sec}$.

From physical reasoning, one might expect the vertical turbulent transport to decrease with increasing Richardson number. Numerous relations have been proposed between $K_{y}$, the vertical diffusion coefficient, and $R_{i}$, the Richardson number (e.g. Munk \& Anderson 1948, also Okubo 1962). Several attempts have also been made to correlate $K_{y}$ with density stratification alone since shear is usually not measured (e.g. Harremoes 1967, Kolesnikov et al 1961, and Koh \& Fan 1969). Koh \& Fan (1969) suggest that in the mks system,

$$
K_{y}=10^{-8} / \varepsilon, \quad 10^{-6}<\varepsilon<10^{-2} m^{-1},
$$

where $\varepsilon$ is the relative density gradient $-\rho_{1}^{-1} d \rho_{a} / d y$. In the surface mixed layer, $K_{y}$ can be expected to depend on the wave characteristics. Golubeva (1964) and Isayeva \& Isayev (1963) proposed relations which may be summarized as

$$
K_{y 0}=0.02 \frac{H}{T^{2}}
$$

where $K_{y 0}$ is the vertical diffusion coefficient at the water surface and $H$ and $T$ are the wave height and period respectively.

\section{Application to Waste-Water Plume}

A Fickian approach with a horizontal diffusivity that changes with the scale is typically used for analysis of the further diffusion of a waste-water plume. Brooks (1960) solved the problem of horizontal turbulent diffusion from a finite line source of pollutant in a steady current ignoring the effects of vertical diffusion and longitudinal dispersion. Several functional forms of dependence between the 
lateral horizontal diffusivity and the plume width were used. Based on the 4/3 law, the result may be summarized as

$$
\frac{c_{\max }}{c_{0}}=\operatorname{erf}\left[\frac{1.5}{\left(1+8 A t w^{-2 / 3}\right)^{3}-1}\right]^{1 / 2} ; \quad t=x / U
$$

where $c_{\text {max }}$ is the maximum concentration in the plume at time $t ; t$ is the time of travel from the source to position $x$ at speed $U ; w$ is the width of the source; $c_{0}$ is the concentration at the source; and $A$ is the coefficient in (27). The ratio $c_{0} / c_{\max }$ may be interpreted as the further dilution obtainable due to transverse diffusion (after that obtained by initial jet mixing) during advective transport for a time $t$ (or equivalently at location $x=U t$ downstream),

This problem, including the effect of vertical diffusion (not necessarily constant), has been solved by Koh \& Fan (1970) numerically. For purposes of waste-water outfalls, $(30)$ is adequate since not only are there other uncertainties such as the proper value of $A$, the changing currents, but also there is the fact that this further vertical diffusion only constitutes a minor part of the overall dilution. It should further be pointed out that the more important part of this phase of mixing and transport is the advective transport rather than the diffusion. It is more important to know where the waste field will go rather than whether the further dilution is 3 or 5 .

The question of the subsequent motions and dispersion of the waste effluent is of importance in assessing the general alteration of the environment. In the overall sense, whatever is discharged to the coastal waters must ultimately be disposed of through transport to the main body of the ocean, sedimentation, or assimilation in the food chain. The ability of a particular coastal environment to accommodate waste effluents is clearly limited by the temporal and spatial scales of flushing currents in relation to the rates of discharges from all the sources in the region. It can be expected that in the steady state there will have to be a general increase in the background levels of pollutant concentrations as a result of the continual discharges. The magnitude of this increase depends on the source strength as well as the flushing efficiency of the body of receiving water. For the coastal environment fronting the open sea, this capability is apparently quite large, but not infinite. There is a limit as to how much waste the receiving water can tolerate before excessive buildup. In semi-enclosed bodies of water such as bays, harbors, and estuaries, the flushing is much reduced and the capacity is correspondingly lower.

To meet shoreline bacterial standards without disinfection, the travel time of the sewage-seawater mixture must be sufficient to allow adequate bacterial die-off. Typically coliform bacterial concentrations are $10^{5}-10^{6} / \mathrm{ml}$ in sewage effluent, and must be reduced to less than $1 / \mathrm{ml}$ for safe shellfish areas or $10 / \mathrm{ml}$ for bathing waters. This means that a reduction of more than $10^{5}$ is necessary; physical dilution of up to $10^{2.5}$ to $10^{3}$ can be achieved in the initial plume mixing and the subsequent ocean diffusion. Consequently a factor about $10^{3}$ is required for coliform disappearance. One order of magnitude decrease takes $4 \mathrm{hr}$ typically 
(although the range might be $1 \mathrm{hr}$ to $8 \mathrm{hr}$ ); thus a minimum travel time to shore of the order of $12 \mathrm{hr}$ is necessary. For this reason, the diffusers are located far from shore (e.g. the new outfall at Orange County, California, discharges more than 21,000 feet offshore).

In the design process, measured ocean currents at the site are usually analyzed to assess the probability of onshore transport and the frequency distribution of travel times to shore (including also the percentage of time that the cloud never goes to shore). Using this information combined with dilution analysis, the performance of the outfall for controlling coliform bacteria can be predicted. In many instances, effluent disinfection is required, all or part of the time, when the oceanographic situation is not favorable enough to achieve natural reduction of coliform bacteria counts to the required standards.

\section{MANIFOLD HYDRAULICS}

The primary purpose of a multiple-port diffuser is to distribute the flow evenly along the entire length of the structure. Thus proper design demands that the discharge per port should be uniform from one end of the diffuser to the other. The design process to achieve this goal involves the solution of a manifold problem (Rawn et al 1961, Vigander et al 1970).

The achievement of a uniform flow distribution is by no means the only requirement for a well-designed diffuser. Other basic hydraulic requirements for sewage effluent include the following: 1. maintaining adequate velocities in the diffuser pipe to prevent deposition; 2. providing a means of cleaning or flushing the system if ever needed; 3. ensuring that no sea water intrusion occurs (i.e. that all ports flow full); 4 . keeping the head loss reasonably small to minimize pumping; and 5. overall simplicity (e.g. avoidance of unnecęssary nozzle gadgets or high maintenance devices).

These requirements have resulted in typical diffusers having the following features: 1. the diffuser pipe diameters are reduced in steps towards the far end; 2. a flap gate is usually provided at the end which can be opened for flushing ; 3 . ports are relatively small, and the total port area downstream of any section is less than the pipe area at that section; 4 . ports are usually simple, bellmouthed holes in the wall of concrete pipe, or simple short nozzles on steel pipe.

\section{Hydraulic Analysis}

A multiport diffuser is basically a long manifold. For the case of sewage effluent discharged into the ocean, the manifold flow problem is complicated by three factors affecting the head and discharge distributions. First, there is a density difference betwecn the sea water outside the diffuser and the sewage effluent inside. Second, hydraulic head loss by friction causes significant changes in internal head along the diffuser. Third, the discharge coefficient for the individual ports is not constant but is a function of both velocity and head within the diffuser pipe. The interplay of these factors in determining the flow distribution has been discussed by Camp \& Graber $(1968,1970)$. 
The flow from a single port can be adequately represented by an equation of the form

$$
Q_{p}=C_{D} A_{p}(2 g E)^{1 / 2},
$$

where $Q_{p}=$ port discharge, $A_{p}=$ port area, $E=$ difference in total head across the port, $g=$ gravitational acceleration, and $C_{D}=$ a discharge coefficient.

The equation is a semi-empirical representation of the Bernoulli equation where the coefficient $C_{D}$ is to account for various losses, contractions, and flow nonuniformities. In general, the value of $C_{D}$ must be found experimentally and depends not only on the geometrical characteristics of the port but also on the ratio of the velocity head in the diffuser to the total head $E$. For a typical port with rounded entrance cast directly into the wall of the diffuser pipe, it has been found that (Brooks 1970a,b)

$$
C_{D}=0.975\left[1-\left(V^{2} / 2 g E\right)\right]^{3 / 8}
$$

while if the entrance is sharp edged

$$
C_{D}=0.63-0.58\left(V^{2} / 2 g E\right) \text {. }
$$

These are based on laboratory experiments performed on ports that are small compared to the diffuser pipe (port diameter less than one-tenth of the pipe diameter).

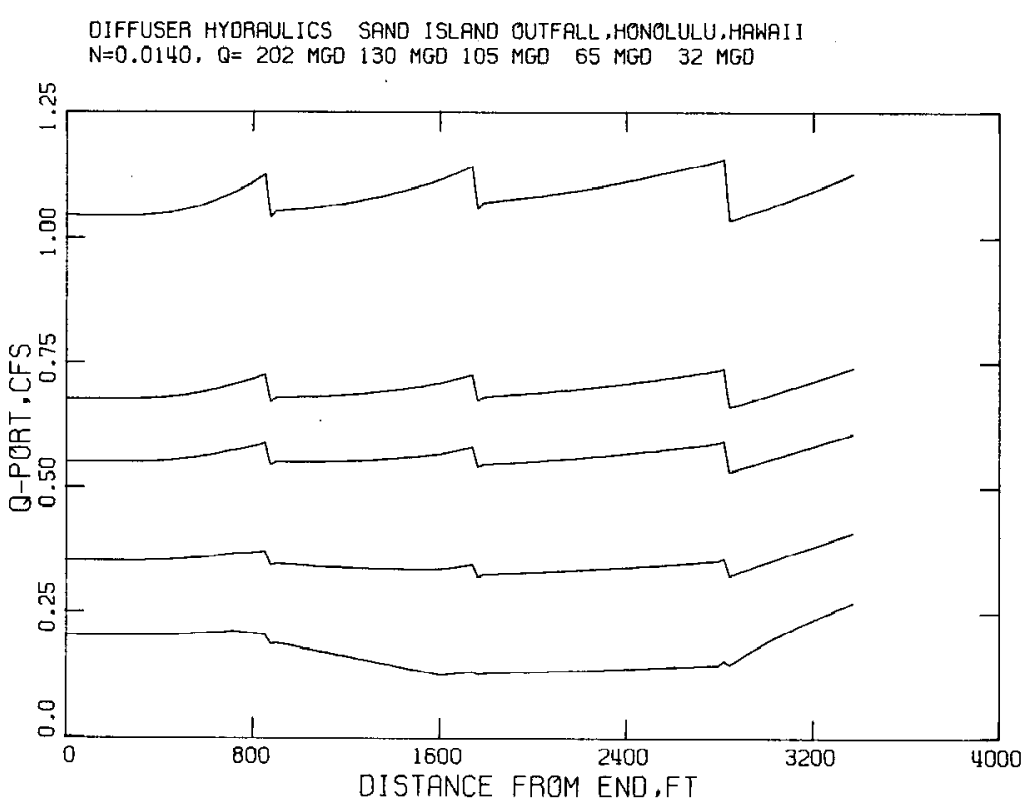

Figure 9 Distribution of discharge along the diffuser used in the Sand Island outfall, Honolulu, Hawaii. 
In some applications, the discharge ports actually consist of riser-nozzle assemblies. Risers are necessary when the main diffuser pipe is completely buried under the ocean bottom. In that event, the discharge coefficient is dependent on the entire geometrical characteristics of the assembly. Experimental data exist on various special configurations (see e.g. Koh \& Brooks 1975).

\section{Calculation Procedure}

An actual diffuser contains many discharge ports and the calculations of the flow through the manifold requires a step-by-step procedure starting from the far end of the diffuser (see e.g. Rawn et al 1961). The value of $E$ is first assumed for the last port. Then the discharge through that port is obtained from (31). This in turn determines the velocity in the pipe. From these, and from the difference in elevation and the density difference between the discharge and the ambient, the value of $E$ for the second port can be obtained, including the allowance for pipe friction. This process is then repeated until the other end of the diffuser is reached. The total flow through the diffuser is simply the sum of all the port discharges.

As an example of a multiple-port diffuser, the hydraulics of the Sand Island outfall diffuser for the City and County of Honolulu is described. The last $3384 \mathrm{ft}$ of the outfall contains 282 ports ranging in diameter from 3.0 to 3.53 inches. The variation of port discharge and velocity in the diffuser pipe are shown in Figures 9 and 10 for a value of Manning $n$ of 0.014 (equivalent to Darcy $f=0.0227$ for 48-inch, 0.0204 for 66-inch, and $f=0.0189$ for 84 -inch pipes used in the diffuser).

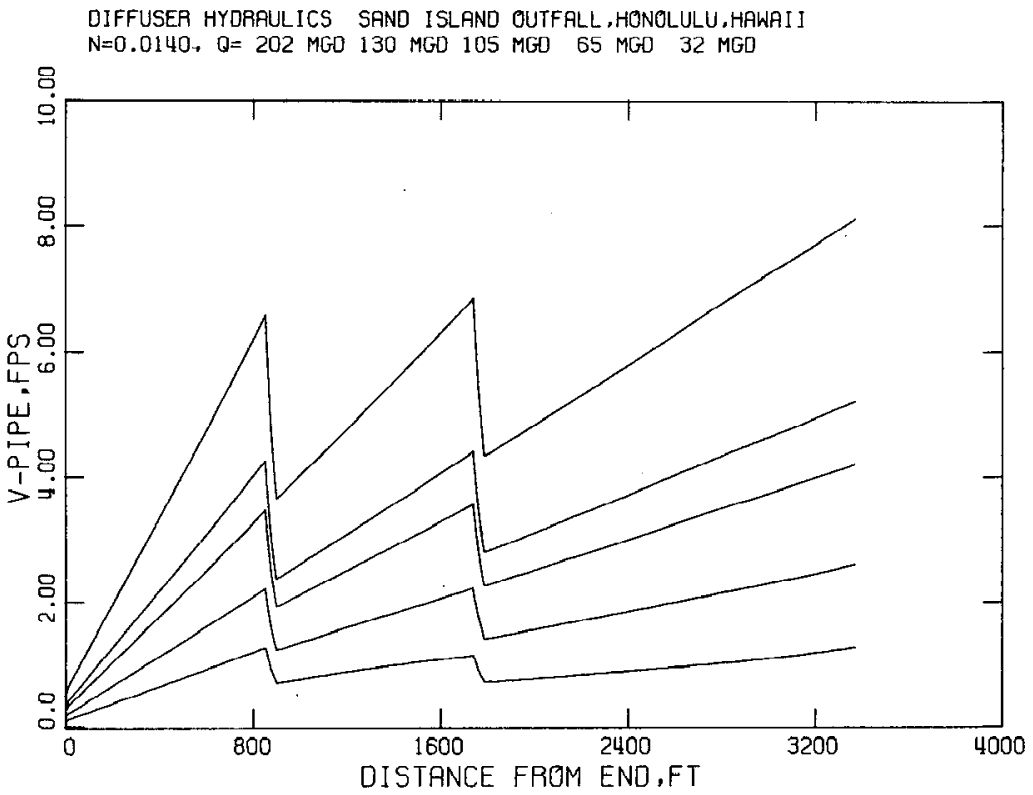

Figure 10 Velocity in the diffuser pipe, Sand Island outfall, Honolulu, Hawaii. 


\section{AN OVERALL ASSESSMENT}

Waste-water discharge into the ocean is practicable for those wastes whose decay times are of the order of days. It is possible, through proper design of large multiport diffusion structures, to ensure that the concentration of the effluent is reduced very rapidly initially. In the immediate neighborhood of the discharge, dilutions of the order of several hundred can be obtained. Through transport and turbulent diffusion, further dilutions of the order of $10 \mathrm{can}$ be achieved so that the increment in pollutant concentration is only $10^{-3}$ (or less) of that in the discharge. Whether higher dilutions can be achieved depends more on regional flushing than on outfall design.

Research efforts are gradually moving toward development of an overall dynamic model for predicting time and space distribution of contaminants introduced from outfalls. So far we have adequate models for only some pieces of the problem with gaps that must be bridged by judgment or common sense in outfall design and analysis. The method of initial introduction of the effluent into the ocean through diffusion structures is the most critically important step and the one for which our models are the best. These structures have great effects on the subsequent concentration distributions because of the ability to make the effluent cloud stay submerged below the surface in a stratified ocean.

\section{ACK NOWLEDGMENT}

This paper was prepared with the support of NSF Grant No. GK35774X.

\section{Literature Cited}

Abraham, G. 1963. Jet diffusion in stagnant ambient fluid. Delft Hydraul. Lab. Publ. $29.193 \mathrm{pp}$.

Abraham, G. 1970. The flow of round buoyant jets issuing vertically into ambient fluid flowing in a horizontal direction. Advan. Water Pollut. Res. Proc. Int. Conf. Water Pollut. Res. 5th Paper III-15, $7 \mathrm{pp}$.

Albertson, M. L., Dai, Y. B., Jensen, R. A., Rouse, H. 1950. Diffusion of submerged jets. Trans. ASCE 115:639-97

Bringfelt, B. 1968. Plume rise measurements at industrial chimneys. Atmos. Environ. 2: 575-98

Bringfelt, B. 1969. A study of buoyant chimney plumes in neutral and stable atmospheres. Atmos. Environ. 3:609-23

Brooks, N. H. 1960. Diffusion of sewage effluent in an ocean current. Proc. Int. Conf. Waste Disposal Mar. Environ. 1st. 246-67. New York: Pergamon

Brooks, N. H. 1970. Conceptual design of submarine outfalls-I. Jet diffusion. Calif. Inst. Technol., W. M. Keck Lab. Tech. Memo. 70-1. $19 \mathrm{pp}$.
Brooks, N. H. 1970. Conceptual design of submarine outfalls-II. Hydraulic design of diffusers. Calif. Inst. Technol., W. M. Keck Lab. Tech. Memo. 70-2. 12 pp.

Brooks, N. H. 1973. Dispersion in hydrologic and coastal environments. Environ. Prot. Agency Rep. 660/3-73-010. 136 pp. (Also Calif. Inst. Technol., W. M. Keck Lab. Rep. KH-R-29)

Brooks, N. H., Koh, R. C. Y. 1965. Discharge of sewage effluent from a line source into a stratified ocean. XI Congr., Int. Assoc. for Hydraul. Res. Pap, No. 2.19

State of California, Water Resources Control Board. Water Quality Control Plan for Ocean Waters of California. July 6, 1972. $15 \mathrm{pp}$.

Camp, T. R., Graber, S. D. 1968. Dispersion conduits. J. Sanit. Eng. Div. Proc. ASCE $94: 31-39$

Camp, T. R., Graber, S. D. 1970. Discussion of Vigander, Elder, and Brooks. $J$. Hydraul. Div. Proc. ASCE 96:2631-35

Carter, H. H., Okubo, A. 1965. A study of the physical processes of movement and dispersion in the Cape Kennedy area. The 
Johns Hopkins Univ. Chesapeake Bay Inst. Rep. NYO-2973-1, Ref. 65-2. 164 pp.

John Carollo Engineers. 1970. Final Report on Ocean Outfall No. 2. County Sanit. Dists. of Orange County

Cederwall, K. 1971. Buoyant slot jets into stagnant or flowing environments. Calif. Inst. Technol., W. M. Keck Lab. Rep. $K H-R-25.86 \mathrm{pp}$.

Csanady, G. T. 1961. Some observations on smoke plumes. Int. J. Air Water Pollut. $4: 47-51$

Csanady, G. T. 1965. The buoyant motion with a hot gas plume in a horizontal wind. J. Fluid Mech. 22:225-39

Csanady, G. T. 1966. Accelerated diffusion in the skewed shear flow of lake currents. J. Geophys. Res. 71(2): 411-20

Csanady, G. T. 1973. Turbulent Diffusion in the Environment. Dordrecht: D. Reidel. $248 \mathrm{pp}$.

Ditmars, J. D. 1969. Computer program for round buoyant jets into stratified ambient environments. Calif. Inst. Technol., W. M. Keck Lab. Tech. Memo. 69-1.27 pp.

Fan, L. N. 1967. Turbulent buoyant jets into stratified or flowing ambient fluids. Calif. Inst. Technol., W. M. Keck Lab. Rep. $K H-R-15.196 \mathrm{pp}$.

Fan, L. N., Brooks, N. H. 1969. Numerical solutions of turbulent buoyant jet problems. Calif. Inst. Technol., W. M. Keck Lab. Rep. No. KH-R-18

Fay, J. A. 1973. Buoyant plumes and wakes. Ann. Rev. Fluid Mech. 5:151-60

Fischer, H. B. 1971. The dilution of an undersea sewage cloud by salt fingers. Water Res. 5:909-15

Fox, D. G. 1970. Forced plume in a stratified fluid. $J$. Geophys. Res. 75:6818-35

Foxworthy, J. E. 1968. Eddy diffusivity and the four-thirds law in near-shore coastal waters. Univ. So. Calif., Allan Hancock Found. Rep. 68-1.72 pp.

Golubeva, V. N. 1964. The formation of the temperature field in a stratified sea. $I z v$. Akad. Nauk SSSR Ser. Geofiz. 1964:77381. Transl. in Bull. Acad. Sci. USSR Geophys. Ser. 1964:467--71

Harleman, D. R. F., Stolzenbach, K. D. 1972. Fluid mechanics of heat disposal from power generation. Ann. Rev. Fluid Mech. $4: 7-32$

Harremoes, P. 1967. Diffuser Design for Discharge to a Stratified Water. The Danish Isotope Center. $18 \mathrm{pp}$.

Hirst, E. A. 1971. Analysis of round, turbulent, buoyant jets discharged to flowing stratified ambients. Oak Ridge Nat. Lab. Rep. ORNL-4685. $37 \mathrm{pp}$.

Hoult, D. P., Weil, J. C. 1972. Turbulent plume in a laminar cross flow. Atmos. Environ. 6:513-31

Isayeva, L. S., Isayev, I. L. 1963. Determination of vertical eddy diffusion in the upper layer of the Black Sea by a direct method. Akad. Nauk Ukrain. SSR Trudy Morsk. Geofiz. Inst. 28:32-35. Transl. in Sov. Oceanogr. Trans. Mar. Hydrophys. Inst., Acad. Sci. USSR 2:22-24

Jirka, G., Harleman, D. R. F. 1973. The mechanics of submerged multiport diffusers for buoyant discharges in shallow water. Mass. Inst. Tech., Ralph M. Parsons Lab. Rep. 169. 313 pp.

Koh, R. C. Y., Fan, L. N. 1969. Further studies on the prediction of the radioactive debris distribution subsequent to a deep underwater nuclear explosion. Tetra Tech, Inc., Rep. TC-154. 354 pp.

Koh, R. C. Y., Fan, L. N. 1970. Mathematical models for the prediction of temperature distributions resulting from the discharge of heated water into large bodies of water. Environ. Prot. Agency Rep. 16130 DWO 10/70. 219 pp. (also Tetra Tech, Inc., Rep. TC-170)

Koh, R. C. Y., Brooks, N. H. 1975. Hydraulic characteristics of discharge nozzles in multiport diffusers. In preparation

Kolesnikov, A. G., Ivanova, Z. S., Boguslavskii, S. G. 1961. The effect of stability on the intensity of vertical transfer in the Atlantic Ocean. Akad. Nauk SSSR Okeanologiva 1:592-99

Kolesnikov, A. G., Panteleyev, N. A., Pisarev, V. D. 1964. Results of direct determination of the intensity of decp turbulent exchange in the Atlantic. Dokl. Akad. Nauk SSSR 155:788-91. Transl. in Dokl. Acad. Sci. USSR Earth Sci. Sect. 155:3-6

Lee, S. L., Emmons, H. W. 1951. A study of natural convection above a line fire. $J$. Fluid Mech. 11:353-68 (1 plate)

Liseth, P. 1970. Mixing of merging buoyant jets from a manifold in stagnant receiving water of uniform density. Univ. Calif., Berkeley, Hydraul. Eng. Lab. Tech. Rep. HEL 23-1.

List, E. J., Imberger, J. 1973. Turbulent entrainment in buoyant jets and plumes. J. Hydraul. Div. Proc. ASCE $99: 1461-74$

Mih, W. C., Hoopes, J. A. 1972. Mean and turbulent velocities for plane jet. $J$. Hydraul. Div. Proc. ASCE 98:1275-94

Morton, B. R., Taylor, G. I., Turner, J. S. 1956. Turbulent gravitational convection from maintained and instantaneous sources: Proc. Roy. Soc. London Ser. A $234: 1-23$ 
Munk, W. H., Anderson, E. R. 1948. Notes on a theory of the thermocline. J. Mar. Res. 7:276-95

Okubo, A. 1962. A review of theoretical models for turbulent diffusion in the sea. J. Oceanogr. Soc. Japan 20th Anniv. vol. : 286-320

Okubo, A. 1968. Summary of our present knowledge of the physical process of mixing in the ocean and coastal waters, and a set of practical guidelines for the application of existing diffusion equations in the preparation of nuclear safety evaluations of the use of nuclear power sources in the sea. The Johns Hopkins Univ., Chesapeake Bay Inst. Rep. NYO3109-40

Okubo, A. 1971. Oceanic diffusion diagrams. Deep Sea Res. 18:789-802

Ozmidov, R. V. 1959. On the dependence of the coefficient of horizontal turbulent diffusion in wind-currents upon the relative depth of a water basin. Izv. Akad. Nauk SSSR Ser. Geofiz. 1959:1242-46. Transl. in Bull. Acad. Sci. USSR Geophys. Ser. 1959:896-99

Ozmidov, R. V. 1965. Turbulent exchange in a stably stratified ocean. Izv. Akad. Nauk SSSR Fiz. Atmos. Okean. 1, no. 8: 853-60. Transl. in Acad. Sci. USSR Atmos. Oceanogr. Phys. 1:493-97

Ozmidov, R. V. 1967. Turbulence and turbulent mixing in the ocean (a brief history of 50 years of research in the USSR). Akad. Nauk SSSR Okeanologiya 7:860-67. Transl. in Acad. Sci. USSR Oceanol. 7:665-70

Priestley, C. H. B., Ball, F. K. 1955. Continuous convection from an isolated source of heat. Quart. J. Roy. Meteorol. Soc. $81: 144-57$

Rawn, A. M., Bowerman, F. R., Brooks, N. H. 1961. Diffusers for disposal of sewage in sea water. Trans. ASCE 126: Part III, 344-88

Richardson, L. F. 1926. Atmospheric diffusion shown on a distance-neighbour graph. Proc. Roy. Soc. London Ser. A 110 : 709-37

Ricou, F. P., Spalding, D. B. 1961. Measurements of entrainment by axisymmetrical turbulent jets. J. Fluid Mech. $11: 21-32$

Rouse, H., Yih, C. S., Humphreys, H. W. 1952. Gravitational convection from a boundary source. Tellus $4: 201-10$

Saffman, P. G. 1962. The effect of wind shear on horizontal spread from an instantancous ground source. Quart. $J$. Roy. Meteorol. Soc. 88:382-93

Schuert, E. A. 1970. Turbulent diffusion in the intermediate waters of the North Pacific Ocean. J. Geophys. Res. 75: 673-82

Sharp, J. J. 1969. Spread of buoyant jets at the free surface. J. Hydraul. Div. Proc. ASCE 95:811-25, 1771-73

Slawson, P. R., Csanady, G. T. 1967. On the mean path of buoyant, bent-over chimney plumes. J. Fluid Mech. 28:311-22

Slawson, P. R., Csanady, G. T. 1971. The effect of atmospheric conditions on plume rise. J. Fluid Mech. 47:33-49

Sotil, C. A. 1971. Computer program for slot buoyant jets into stratified ambient environments. Calif. Inst. Technol., W. $M$. Keck Lab. Tech. Memo. 71-2. 21 pp.

Southern California Coastal Water Research Project. 1973. The ecology of the Southern California bight: implications for water quality management. SCCWRP Rep. TR 104. $531 \mathrm{pp}$.

Telford, J. 1966. The convective mechanism in clear air. J. Atmos. Sci. 23:652-66

R. M. Towill Corp. 1972. Final Design Report Sand Island Ocean Outfall System, City and County of Honolulu

Vigander, S., Elder, R. A., Brooks, N. H. 1970. Internal hydraulics of thermal discharge diffusers. J. Hydraul. Div. Proc. $A S C E$ 96:509-27

Webster, C. A. G. 1964. An experimental study of turbulence in a density-stratified shear flow. J. Fluid Mech. 19:221-45 


\section{CONTENTS}

Some Memories of Early Work in Fluid Mechanics at the Technical UNIVERSITY OF DELFT, J. M. Burgers

Pressure Fluctuations Beneath Turbulent Boundary Layers, $W . W$. Willmarth

Nonlinear Thermal Convection, Enok Palm

Relaxation Methods in Fluid Mechanics, Harvard Lomax and Joseph L. Steger

Experiments in Granular Flow, $K$. Wieghardt

Flow Lasers, Walter H. Christiansen, David A. Russell, and Abraham Hertzberg

The Structure and Dynamics of Vortex Filaments, Sheila E. Widnall 141

Fluid Mechanics of Heat Pipes, C. L. Tien

Fluid Mechanics of Waste-Water Disposal in the Ocean, Robert C. Y. Koh and Norman H. Brooks

HemodynamiCs, H. L. Goldsmith and R. Skalak

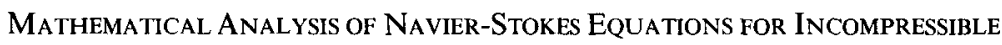
Liquids, O. A. Ladyzhenskaya

EXPERIMENTS IN Rotating and Stratified Flows: OCEANOGRAPHIC Application, T. Maxworthy and F. K. Browand

New Trends in Experimental Turbulence ResearCh, John Laufer 307

The Effect of Waves on Rubble-Mound Structures, Fredric Raichlen 327

Hydrodynamics of LaRge Lakes, G. T. Csanady 357

\section{INDEXES}

AUTHOR INDEX

Cumulative Index of Contributing Authors, Volumes 3-7 394

Cumulative IndeX of Chapter Titles, Volumes 3-7 